\title{
A VIVÊNCIA DE MÃES DE RECÉM-NASCIDOS PREMATUROS NO PROCESSO DE LACTAÇÃO E AMAMENTAÇÃO
}

\author{
The living of preterm newborn's mother in the process of \\ lactation and breastfeeding
}

\section{La vivencia de las madres de recién nacidos prematuros en el proceso de la lactación y de amamentación}

\author{
Rosangela Venancio da Silva ${ }^{1}$
}

Isilia Aparecida Silva ${ }^{2}$

\begin{abstract}
RESUMO
Este estudo qualitativo teve como objetivo geral compreender a vivência da amamentação de mães de recém-nascidos prematuros durante a internação de seus filhos e como objetivo específico descrever a performance de amamentação e condições de suas mamas e lactação, por ocasião da alta dos filhos. Adotaram-se o modelo Pesando Riscos e Benefícios como referencial de análise e o método do Discurso do Sujeito Coletivo para organização dos dados. Participaram do estudo 11 mulheres, mães de bebês prematuros internados na Unidade Neonatal do HU-USP. A entrevista semiestruturada possibilitou a elaboração de oito Discursos do Sujeito Coletivo listados em dois blocos com os seguintes temas: "Lactação e amamentação" e "Contexto hospitalar e doméstico", que possibilitaram de compreensão de que as mães deste estudo vivenciam um processo de avaliação contínua das condições de saúde, crescimento e desenvolvimento da criança, que contribui para sua motivação para amamentar e direciona suas ações no prosseguimento da amamentação.
\end{abstract}

Palavras-chave: Lactação. Aleitamento Materno. Prematuro. Cuidados de Enfermagem.

\begin{abstract}
This qualitative study aimed on the whole to understand the breastfeeding living experience of preterm newborn's mothers, throughout the admission of their children and as specific objectives to describe the breastfeeding performance, and their lactation and breasts' conditions during their children's hospital discharge. It was adopted the model Weighing Risks and Benefits, as analysis referential and the method of Collective Subject for organizing data. Eleven women attended the study, in which they were mothers of preterm infants admitted at the Neonatal Unit of HU-USP. The semi-structured interview made it possible the creation of eight Collective Subject Discourses, listed in two groups with the following themes: Lactation and breastfeeding and Hospital and home contexts, which made it possible to understand that the mothers of this study lived a process of ongoing evaluation of the child's health, growth and development conditions, which contributes to their motivation to breastfeed and guides their actions in keeping breastfeeding.
\end{abstract}

Keywords: Lactation. Breast Feeding. Infant, Premature. Nursing Care.

\section{Resumen}

Este estudio cualitativo ha tenido como objetivo general, comprender la vivencia de amamentación de madres de recién nacidos prematuros, durante la internación de sus hijos y como objetivos específicos describir el desempeño de la amamantación y condiciones de sus mamas y lactación, en el momento del alta de sus hijos. Se ha adoptado el modelo: Pesando riesgos y beneficios, como referencial de análisis y el método del Discurso del Sujeto Colectivo para organización de los datos. Han participado del estudio 11 mujeres, madres de bebes prematuros, internados en La Unidad Neonatal del HU-USP. La entrevista semi estructurada ha posibilitado la elaboración de ocho Discursos del Sujeto Colectivo listados en dos bloques con los siguientes temas: Lactación y Amamantación y Contexto de hospital y doméstico, que han posibilitado comprender, que las madres de este estudio han vivenciado un proceso de avaluación continuado de las condiciones de salud, crecimiento y desarrollo del niño que ha contribuido para su motivación en amamantar y que ha diseccionado sus acciones en el proseguimiento de la amamantación.

Palabras clave: Lactancia. Lactancia Materna. Prematuro. Atención de Enfermería.

\footnotetext{
${ }^{1}$ Enfermeira da Unidade Neonatal do Hospital Universitário da Universidade de São Paulo. Mestre em Enfermagem pela Escola de Enfermagem da USP. Brasil. Email: rosangvs@ig.com.br, ${ }^{2}$ Professora Titular do Departamento de Enfermagem Materno-Infantil e Psiquiátrica da Escola de Enfermagem da Universidade de São Paulo. Diretora da Escola de Enfermagem da Universidade de São Paulo. Brasil. E-mail: isasilva@usp.br
} 


\section{INTRODUCÃO}

0 desenvolvimento de recursos tecnológicos e assistenciais tem aumentado as chances de sobrevivência dos neonatos prematuros. No entanto, mesmo com toda a disponibilidade de equipamentos de reanimação e monitoração e de profissionais de saúde altamente qualificados, as dificuldades em relação à alimentação, em especial à amamentação de bebês prematuros ainda é motivo de preocupação.

Frequentemente em nosso serviço, precisamos buscar mulheres doadoras de leite humano, priorizando o receptor mais vulnerável. Embora estimuladas pela equipe e pelas atividades de incentivo e apoio do Banco de Leite Humano do Hospital Universitário da Universidade de São Paulo (HU-USP), para manutenção da lactação e a amamentação, observamos que as mães de bebês prematuros têm maior dificuldade de instalar ou manter a amamentação.

Assim, partimos de nossas observações na prática, que mães de bebês prematuros muitas vezes têm dificuldade em manter a lactação durante o período de internação de seus filhos, e, com frequência, estes não estão sendo alimentados exclusivamente ao seio materno, por ocasião da alta hospitalar, embora as mães sejam orientadas a estimularem a lactação e amamentar. Portanto, emerge o questionamento sobre quais fatores, além dos biológicos, poderiam compor as condições de lactação e amamentação de mães de prematuros que encontramos atualmente em nosso serviço.

A reflexão motivou este estudo por considerarmos que 0 conhecimento sobre os elementos que possam interferir na lactação e processo de amamentação das mães de bebês prematuros dar-nos-á melhores condições para o planejamento de uma assistência mais aproximada das necessidades dessas nutrizes.

Assim sendo, o objetivo geral deste estudo foi compreender a vivência da amamentação de mães de recém-nascidos prematuros durante a internação de seus filhos e o objetivo específico foi descrever a performance de amamentação e condições de suas mamas e lactação, por ocasião da alta dos filhos.

\section{MÉTODO}

Considerando que este estudo visa à compreensão da vivência de amamentação de mães de recém-nascidos prematuros, com a busca dos elementos do contexto da experiência dessas mulheres, envolvidos no processo de lactar e amamentar, a abordagem qualitativa pareceu-nos mais conveniente.

A abordagem qualitativa proporciona ao pesquisador a possibilidade de tentar compreender a maneira como as pessoas pensam e reagem diante das questões focalizadas; auxilia 0 investigador a conhecer a dinâmica e a estrutura da situação estudada do ponto de vista de quem a vivencia; ajuda a compreender melhor a distância entre o conhecimento e a prática; colabora na compreensão dos sentimentos, valores, atitudes e temores das pessoas, explicando suas ações diante de um problema ou situação ${ }^{1}$

Também, utilizamos o modelo teórico "Pesando Riscos e Benefícios" como base para análise dos dados, que nos dá elementos para a compreensão do processo de amamentação das mães participantes do estudo.

0 estudo foi realizado na Unidade Neonatal do HU-USP, localizado na cidade de São Paulo. Trata-se de um hospital de ensino e pesquisa, que presta serviços à comunidade. A coleta de dados foi iniciada após aprovação e autorização da Comissão de Ensino e Pesquisa (COMEP) e do Comitê de Ética em Pesquisa (CEP), do HU-USP, registro CEP-HU/USP $n^{0} 721 / 07$, obtendo assim permissão para uso do nome da instituição.

A pesquisa atendeu aos requisitos éticos vigentes da Resolução 196/96 do Conselho Nacional de Saúde 3.

A população do estudo foi composta por 11 mulheres que deram à luz no HU-USP, sadias do ponto de vista clínico, que aceitaram participar da pesquisa e que tinham aparentemente mamas consideradas aptas para a lactação, mamilos do tipo protruso ou semiprotruso, e sem impedimentos para amamentar. Ainda, eram mães de crianças prematuras, com idade gestacional ao nascimento de 29 e 4/7 semanas a 33 e 6/7 semanas, sem anomalias e patologias que poderiam impedir ou dificultar a amamentação, internadas no setor de cuidados intermediário ou semi-intensivo da Unidade Neonatal, que permaneceram no hospital por um período mínimo de 15 dias.

A identificação dos sujeitos da pesquisa ocorreu durante o cotidiano da assistência desenvolvida na Unidade Neonatal e a consulta aos prontuários dos bebês. A coleta dos dados subjetivos foi feita por meio de entrevista semiestruturada, que buscou explorar a experiência de amamentação da mulher, para identificar os elementos interferentes na manutenção da lactação e amamentação de seu bebê prematuro. A entrevista foi iniciada pela questão norteadora: "Conte-me como foi sua experiência de amamentar seu bebê do começo ao fim da internação dele (a)", e aprofundada por outras questões, conforme a necessidade, no decorrer do processo. A entrevista foi gravada em equipamento próprio, após o consentimento da mulher. Os dados objetivos, retirados do prontuário, bem como as condições de mamas, mamilos e volume lácteo, foram obtidos por meio do exame das mamas. A obtenção dos dados foi feita no dia anterior à alta da criança em local privativo.

Os conteúdos das entrevistas foram organizados tendo como base a proposta metodológica do Discurso do Sujeito Coletivo (DSC), que consiste em uma estratégia metodológica a qual utiliza a abordagem discursiva, com o objetivo de tornar mais claros, organizar e apresentar os dados qualitativos de natureza verbal ${ }^{4}$.

Todo conteúdo verbal de cada uma das falas obtidas foi analisado, extraindo-se delas as expressões-chave que deram origem às idéias centrais de cada um dos depoimentos ${ }^{4}$. Posteriormente, as expressões-chave foram agrupadas conforme sua significação aproximada e analisadas para compor os discursos, emergindo daí oito Discursos do Sujeito Coletivo, representando, assim, os relatos das mulheres participantes da pesquisa. 


\section{APRESENTAÇÃO E DISCUSSÃO DOS RESULTADOS}

A maioria das mulheres participantes tinha idade superior a 25 anos, sendo $72,7 \%$ entre 26 e 40 anos e $27,2 \%$ entre 16 e 19 anos. Das 11 participantes do estudo, sete delas $(63,6 \%)$ estavam sendo mães pela primeira vez; as demais tinham entre um e três filhos.

Pelo exame físico, observamos que sete mulheres $(63,6 \%)$ tinham mamas flácidas bilaterais. Mamas ingurgitadas foram detectadas em quatro mulheres $(36,3 \%)$, das quais duas apresentavam esta condição bilateralmente e duas, em apenas uma das mamas. Mamas túrgidas não estavam presentes em nenhuma mulher participante deste estudo.

Todas as mulheres tinham mamilos íntegros, e mamilos protrusos estavam presentes em oito mulheres $(72,7 \%)$ e, destas, apenas uma $(9 \%)$ apresentava mamilo direito protruso e mamilo esquerdo semiprotruso. Mamilos semiprotrusos bilaterais estavam presentes em duas mulheres. Nenhuma das mães de nosso estudo tinha mamilo pseudoinvertido ou malformado, ou mamilo invertido ou umbilicado.

No exame físico, percebemos que a maior parte das mulheres tinha mamas consideradas aptas para a lactação e amamentação. No entanto, a observação da flacidez mamária bilateral em $63,6 \%$ das mulheres nos faz pensar no período em que foi realizado o exame físico das mamas, pois apenas uma delas encontrava-se no período puerperal de 24 dias, as demais tinham dado à luz há mais de um mês.

As duas mulheres que apresentavam mamilos semiprotrusos bilaterais demonstraram ainda estar aprendendo a lidar com as dificuldades no manejo da amamentação; no entanto, amamentavam seus bebês ao peito com complementação láctea, por ocasião da alta.

A produção láctea em média quantidade foi observada em seis mulheres (54,5\%), em ambas as mamas. Duas (18,1\%) apresentavam pequena quantidade de leite em ambas as mamas, e duas (18,1\%) tinham média quantidade de leite na mama esquerda e pequena quantidade na mama direita. Apenas uma mulher (9\%) apresentava pequena quantidade de leite na mama direita e drenagem ausente em outra mama, e seu bebê iniciou sucção ao peito nos $86^{\circ}$ dias de vida.

Podemos constatar que a ausência de drenagem láctea em uma das mamas foi observada na mãe do bebê prematuro que permaneceu mais tempo internado, iniciando sucção ao peito também tardiamente.

A frequência de realização das ordenhas mamárias variou entre as mulheres participantes do estudo; oito delas $(72,7 \%)$ realizavam o procedimento de duas a três vezes ao dia, enquanto as demais $(27,2 \%)$ referiram não manter regularidade na frequência de realização das ordenhas, durante o período no qual seu bebê esteve internado. Vale ainda ressaltar que, das mulheres de nosso estudo que amamentavam seus bebês exclusivamente ao peito, por ocasião da alta, uma manteve regularidade na frequência das ordenhas e permanecia com o filho, em média, 12 horas diariamente.

A frequência de ordenhas deve ser semelhante ao número de mamadas do bebê, ou seja, aproximadamente oito a dez vezes ao dia, com o intuito de estimular a liberação de prolactina e permitir a produção de leite por mais tempo em quantidade suficiente ${ }^{5}$.

Os bebês prematuros das mães participantes do estudo, nascidos no HU-USP no período de janeiro a julho de 2007, tiveram idade gestacional ao nascimento de 29 e 4/7 semanas a 33 e 6/7 semanas. 0 peso ao nascimento desses bebês foi de 830 gramas a 2.140 gramas. 0 peso na alta variou de 2.135 a 2.675 gramas, e o período de internação, de 24 a 113 dias. Todos os bebês receberam leite humano do Banco de Leite do HU-USP durante o período de internação. Na alta hospitalar, $81,8 \%$ das crianças eram alimentadas ao seio materno e recebiam complemento lácteo. Apenas dois bebês (18,1\%) estavam em aleitamento materno exclusivo.

\section{APRESENTACCÃO DOS DISCURSOS DO SUJEITO COLETIVO}

Os oito Discursos do Sujeito Coletivo (DSC) elaborados compuseram dois temas: "Lactação e amamentação" e "Contexto hospitalar e doméstico".

1. Os DSC referentes à "Lactação e amamentação" discorrem sobre as etapas vivenciadas pelas mulheres do estudo quando, logo após o nascimento do filho prematuro, iniciam o processo para manutenção da lactação, enquanto a criança não mama diretamente ao peito. Os discursos apontam ainda como as mães dos bebês prematuros experienciam as dificuldades para manutenção da lactação e manejo da amamentação, bem como aprendem a superar esses obstáculos, em prol da saúde do filho, visto que, na percepção dessas mulheres, amamentar o bebê prematuro torna-se essencial para seu crescimento e desenvolvimento saudável.

\section{DSC Preocupando-se com a produção de leite enquanto não amamenta}

[...] Assim, tirava a todo o momento, mas foi difíil porque não sei, o leite ia diminuindo. Com a ordenha saía no começo e depois de alguns dias não saía mais. Em casa, quase não conseguia tirar porque tinha pouco leite quando ele ainda não mamava no peito. Quando eu vi o leite diminuindo, fiquei desesperada [..]. Eu percebia que não estava adiantando muito, pois, quando eu tirava, não saia muito mesmo, porque tinha que sugar, se ele não sugasse não ia descer mais leite, acho que por ele ter sido prematuro, também [..]. Fiquei um pouco triste, porque eu não estava tendo produção de leite... É engraçado, em casa não sai, às vezes só sai quando eu venho perto dele[...]. De ter diminuído, um pouco foi o medo, o cansaço, também o estresse, às vezes; eu estava num lugar, por 
exemplo, aqui no Berçário, daqui a pouco estava na UTI. A força de vontade de o meu filho viver, esta foi a força maior, eu creio de estar com leite até agora.

As mulheres deste estudo inicialmente se empenham para manter a lactação, porém, com o decorrer do período de internação do bebê, observam que, mesmo seguindo as orientações recebidas para manutenção da lactação, não conseguem evitar a diminuição de sua produção láctea. Demonstram preocupação e sentem-se cada vez mais impotentes ao observar o volume de leite diminuindo. Perante tal situação, consideram a ausência da sucção do recém-nascido ao peito como principal razão para a diminuição de sua produção de leite. Sabem da importância da estimulação manual das mamas e ordenha mecânica como procedimentos de grande auxílio, mas, segundo elas, tornam-se ineficazes quando realizadas por período prolongado. No entendimento dessas mães, nada do que fizerem na tentativa de manter a lactação será eficiente se seu bebê não mamar no peito. A sucção diretamente ao peito é o principal fator para o sucesso na manutenção da lactação, segundo elas.

Estudo realizado com mães de bebês prematuros internados em UTI Neonatal verificou que, para essas mães obterem sucesso na manutenção da lactação durante esse período, é preciso que elas se sintam seguras, tenham orientação e apoio da família e dos profissionais de saúde ${ }^{6}$.

Nesse sentido, as mães dos bebês prematuros buscam colocar em prática as recomendações recebidas na tentativa de não cessar totalmente sua produção de leite, qualificando como ideal a produção necessária para suprir as necessidades alimentares do filho. As mulheres vêem a prematuridade do filho como uma condição desfavorável, entre outras, para o sucesso na manutenção da lactação. Percebem-se ansiosas pela demora para iniciar a amamentação, e consideram que a ansiedade contribui para a diminuição de sua produção láctea. Expressam que passam por situação desgastante por terem tido o filho prematuro e este permanecer internado. Além do cansaço físico, sentem-se inseguras em relação à saúde dele, quando têm a percepção de sua instabilidade. Atribuem a esse contexto, ou seja, às condições físicas do filho e também a seu próprio estado físico e emocional, fatores contribuintes para agravar sua produção láctea.

Acompanham a progressão do filho e sentem-se motivadas quando, finalmente, constatam a melhora da saúde dele, verificando ainda o aumento de sua produção de leite quando seu bebê finalmente suga no peito. Interpretam que os obstáculos enfrentados e superados pelo bebê, durante esse período, serviram de motivação para prosseguirem na tentativa de manterem sua produção de leite.

\section{DSC - Encontrando dificuldades para amamentar}

[...] Às vezes, ele nem mamava no peito, e eu ficava super triste porque oferecia, oferecia, ele não tinha estímulo, não conseguia, e também não saía muito leite. Assim... eu tive um pouco de dificuldade, e ele teve um pouco de dificuldade porque tava usando a sonda. Porque na sonda não tinha fome, então, se ele não tinha fome, não tinha estímulo pra sugar.[...] Então, às vezes, eu também achava ruim, porque eu não sabia quando ele pegava direito.[...] Porque nasceu prematuro, tem mais dificuldade para puxar, para sugar, mama bem mais devagar, é mais sonolento, tem mais preguiça, demora mais, é mais cansativo.

Pela fala das mulheres desse discurso, observamos que elas não sentem como prazeroso o início da amamentação e atribuem as dificuldades encontradas para amamentar ao fato de o bebê não sugar, mesmo quando estimulado, o que, segundo a sua percepção, dificulta a saída do leite. Como já mencionado, associam sua baixa produção de leite à dificuldade de sucção da criança, estes como fatores essenciais para tornar o processo de amamentação ainda mais dificultoso, e entristecem-se com isso.

Mesmo as mulheres que vêem o aleitamento como biologicamente natural, percebem limites em sua prática e sentem necessidade de aprender, mostrando que o ato de amamentar não é tão fácil, natural e instintivo. Esta condição tem provocado nas mulheres sentimentos de que não estão aptas para a função de nutrizes ${ }^{7}$.

As mães observam o comportamento e as manifestações do bebê e interpretam a prematuridade do filho como agravante para se estabelecer a amamentação. Consideram o uso da sonda gástrica do filho como fator de empecilho para ambos, ou seja, dificuldade de sucção da criança, dificuldade no manejo da amamentação pela mulher, e, ainda, na avaliação que esta faz para verificar se o filho está sendo bem alimentado.

Em estudo realizado com mães de bebês prematuros, participantes do Método Canguru, foi observado que as mulheres tiveram dificuldades no manejo e amamentação do filho, e que essas dificuldades estavam relacionadas ao baixo peso do bebê, à dificuldade para manter calor e sugar. Observouse ainda que a dificuldade para sugar e a diminuição da lactação geravam na mãe grande tensão em razão da ênfase na amamentação ${ }^{8}$.

A necessidade de a criança permanecer internada logo após o nascimento pode contribuir para a vivência da mãe do bebê prematuro se tornar difícil, e a dificuldade atribuída por essas mulheres ao processo de amamentar parece estar relacionada com a fragilidade de seus filhos, é o que concluiu estudo com mães de bebês prematuros em Unidade Neonatal ${ }^{9}$.

A avaliação contínua de suas condições de amamentar e das condições do bebê de ser amamentado, bem como a interpretação das manifestações de comportamento da criança, demonstram que as mulheres mães de bebês prematuros avaliam, a cada oportunidade de amamentação ou contato com o filho, o processo de amamentar, buscando elementos para ponderar sobre o que este "meio" de alimentação pode estar trazendo risco ou benefício à criança. Por outro lado, também avaliam em que condições ela e o bebê prosseguem nessa empreitada. 


\section{DSC - Superando dificuldades na amamentação}

[...]Depois que tirou a sonda, aí eu percebi que ele pegava bem. Melhorou muito, cada dia que passa ele vai se aprimorando mais. [...] Eu senti, notei uma diferença bem grande de melhora maior depois no peito, depois da amamentação, ele passou a pegar mais peso, ficar assim mais ágil, mais vivo, eu senti ele muito mais vivo.

Observam o comportamento e as manifestações do bebê e avaliam que a amamentação vai se instalando com o decorrer dos dias. Consideram a ausência da sonda gástrica o principal motivo para melhora da sucção da criança, propiciando, assim, seu desenvolvimento e crescimento, à medida que conseguem se alimentar sem o uso da sonda. Pelo discurso, podemos apreender que as mulheres começam a se sentir confiantes em relação à saúde do filho, quando percebem a melhora da aceitação dele ao peito, vão aos poucos vencendo os obstáculos iniciais da amamentação e constatando a evolução gradativa do processo.

Geralmente, a mãe observa o filho e detecta nele as manifestações de comportamento que para ela constituem formas de comunicação do bebê, consideradas como indicadores importantes para entender o estado de saúde e alimentar da criança $\mathrm{a}^{2}$. Segundo o modelo Pesando Riscos e Benefícios ${ }^{2}$, na experiência da amamentação, a mulher assume o papel de provedora do alimento, e um dos indicadores qualitativos desse seu desempenho é sua observação quanto ao bem-estar da criança.

Em nosso estudo, o bem-estar assume o significado de recuperação, representado tanto pelo crescimento e desenvolvimento da criança, avaliado pelo ganho de peso e aumento da força de sucção, como pela manifestação dos comportamentos do bebê que fazem com que a mãe o considere "mais vivo", ou seja, revitalizado pelo leite materno.

\section{DSC - A importância do leite materno e da amamentação para o bebê e a mãe}

\begin{abstract}
[...]Eu queria que ele mamasse o meu leite, especialmente só o meu leite.[...] Acho que leite materno é essencial de tudo, para pegar amor, por tudo, porque só de a gente saber que ele está mamando e o leite do peito é muito importante, é a proteção dele. Por ele ser prematuro, vai ajudá-lo a se desenvolver mais rápido. [...] Estou realizada, tinha vontade de amamentar, sempre tive. Você sendo mãe, mas sem amamentar, eu acho que não está sendo mãe completa.[...] Quando a gente pega a criança no colo e amamenta, acho que o amor aumenta mais.
\end{abstract}

Por esse discurso, percebemos a ênfase dada pela mãe ao leite materno, como sendo o alimento ideal para o filho, tanto para sua nutrição como para sua proteção.
Em estudo realizado sobre as representações sociais do aleitamento materno para mães de bebês prematuros em Unidade de Cuidado Canguru, foi observado que a representação do leite materno como proteção parece estar relacionada às particularidades de ter um bebê prematuro, em que é atribuído ao leite materno o poder de recuperar a criança, que, na visão dessas mães, não é um bebê saudável ${ }^{10}$. Observou-se também que uma das representações da amamentação para mães de recém-nascidos prematuros foi a relação que elas estabeleciam entre o leite materno e crescimento e desenvolvimento saudável. Para os autores, isso se deve ao fato do resultado da interpretação, pelo senso comum, das campanhas que têm propagado a relação entre crescimento e desenvolvimento saudável e o leite materno ${ }^{10}$.

Além de a amamentação representar um ganho ou benefício para a saúde da criança, encontramos nas falas das mulheres de nosso estudo um discurso que reproduz o papel social materno propagado junto às mulheres, que atribuem à pratica da amamentação a representação da realização feminina da maternidade.

A obrigatoriedade e o cumprimento dos deveres embasados nos pressupostos do papel e função que têm de desempenhar, de um ato instintivo e natural, colaboram para a percepção da amamentação como uma tarefa a ser realizada sempre com sucesso ${ }^{11}$.

Da mesma forma, podemos dizer que, neste estudo, as mulheres avaliam como prioritárias as necessidades de seu bebê prematuro, interpretando como benefício para ele ser amamentado, assegurando, assim, em sua percepção, melhores condições para que seja uma criança saudável.

2. Os DSC referentes à "Lactação e amamentação" discorrem sobre as etapas vivenciadas pelas mulheres do estudo quando, logo após o nascimento do filho prematuro, iniciam o processo para manutenção da lactação, enquanto a criança não mama diretamente ao peito. Os discursos apontam ainda como as mães dos bebês prematuros experienciam as dificuldades para manutenção da lactação e manejo da amamentação, bem como aprendem a superar esses obstáculos, em prol da saúde do filho, visto que, na percepção dessas mulheres, amamentar o bebê prematuro torna-se essencial para seu crescimento e desenvolvimento saudável.

\section{DSC - Minimizando a separação por meio do contato físico com o bebê}

[...] Eu me sentia triste, parecia que estava faltando alguma coisa, tive até mesmo o começo de uma depressão muito forte.[...] Creio que todas as mães que tiveram seus bebês prematuros se sentem totalmente perdidas. [...] Era uma outra emoção que eu nunca tinha tido antes, era uma energia muito diferente, muito mais forte do que só tá olhando, cada vez que eu encostava nele, eu sentia que ele tinha uma sensação maior, sabe, emotiva, acho que eu mexia com as emoções dele. [...] 0 que eu passei, os contratempos, não cobre a minha felicidade maior do que eu ver o meu filho e estar 
podendo sair com ele, minha felicidade maior porque eu achava que ia perder o meu filho...

Um dos aspectos importantes para o desenvolvimento do sentimento de proximidade e maternidade está no fato de a mãe poder pegar a criança em seus braços e prestar cuidados, mesmo que estes sejam mínimos ao bebể ${ }^{12}$ Assim, neste estudo, observamos, também, que a prematuridade é percebida pela mãe como um fator de distanciamento entre ela e o filho, em que ocorre não apenas uma condição de cuidados especiais para ele, mas a ruptura de um processo o qual ela e o bebê estavam vivendo, a gravidez. Para a mãe do bebê prematuro deste estudo, o nascimento do filho provoca um sentimento de perda e sofrimento para ela, o que é aumentado com sua interpretação de perda e sofrimento, também sentidos pela criança.

Em estudo realizado com abordagem fenomenológica com mães de bebês prematuros internados, o autor analisou sentimentos e reações das mães diante da condição de prematuridade do filho e concluiu que, dentre as dificuldades vivenciadas pela mãe do bebê prematuro, encontra-se o que ela considera a não-realização de seu papel como mãe. Ela se sente ressentida por não poder realizar a maternidade tal como deveria ser, em razão dos obstáculos encontrados, tanto pelas condições da prematuridade do filho como pela estrutura da UTI neonatal ${ }^{13}$.

$\mathrm{Na}$ construção desse discurso, percebemos que as mulheres vão valorizando o contato físico com seu frágil bebê, evidenciando essa aproximação como elemento essencial para interagir com a criança, além de contribuir para a progressão da saúde do filho. 0 nascimento de um bebê diferente do que foi esperado, como o prematuro, aquele com malformações ou outras doenças, pode causar na mãe forte impacto psicológico. Ela poderá ter reações de luto, como pena pela fragilidade do filho, medo de seu provável óbito, sentimento de fracasso por não ter levado a gravidez a termo ${ }^{14}$.

Pelo que se pode apreender deste discurso, as mães acompanham a evolução de seu bebê, avaliando e interpretando as manifestações dele durante o contato físico, e pontuam como positivas a interação entre ambos para o melhor desenvolvimento do filho.

\section{DSC - Cada um ajuda um pouco}

Em casa, davam bastante incentivo, me apoiavam bastante, estão me apoiando. [...] Meu marido que foi a base de tudo. [...] Cada um ajuda um pouco, tanto aqui no Hospital como lá em casa.

0 ambiente doméstico exerce papel seguramente decisivo para as condições de superação das dificuldades, que vão desde a liberação do tempo para permanecer no hospital ao sentimento de ambiguidade provocado pelos diferentes papéis e diversidade das tarefas que a mãe sente ser de sua responsabilidade. No contexto hospitalar, o papel do profissional aparece como elemento de grande importância para amparo e estímulo para a mãe do prematuro superar medos e inseguranças.
Embora seja para a mãe uma experiência solitária, algum tipo de ajuda que receba contribui para sua força, que é essencial para que ela vivencie seu papel de acompanhante. A mãe sentese ajudada quando tem o apoio e solidariedade das pessoas que se preocupam com a criança e com ela, essas pessoas são os familiares, amigos e alguns profissionais ${ }^{15}$.

\section{DSC - Tendo que dividir seu tempo e atenção}

[...] Eu me cobrava muito porque você quer dar para todo mundo o mesmo tanto, então você tem que conseguir assim para você se dividir.[...] O neném está no hospital, mas ele estava bem cuidado, então você vai, vem um pouco aqui, faz um pouco lá.... [...] A gente sente, assim sabe, que parece que está deixando um de lado para dar atenção para o outro. [...] Mesmo você vindo aqui olhar o teu filho, você não se entrega a ele entendeu? Porque você deixa a sua... sua outra parte em casa. Não é todo mundo que tem estrutura não, para ficar vindo, cuidando, porque muda a rotina totalmente da pessoa. Mulher é sexo forte, sei que falam que é sexo frágil, não sei da onde.

As mães dos bebês prematuros cobram-se e vêem-se com poucas condições para atender a todos da maneira que desejariam, vivem uma situação conflitante; de um lado, querendo se dedicar ao filho internado; mas para que isso ocorra precisam abdicar em parte da assistência aos outros filhos e aos familiares.

Mães acompanhantes referem que, em alguns momentos, sentem que não estão dando conta de responder a todos os papéis que consideram como seus. Assim, percebem-se desejando cumprir com seus deveres para com o filho internado e com os demais membros da família. Diante disso, sentem-se divididas, pressionadas e sobrecarregadas, pois não conseguem se desligar e encontram-se no limite de suas forças ${ }^{15}$.

A necessidade de ficar com o bebê internado e, ao mesmo tempo, precisar deixar os outros membros da família e sua casa é uma situação conflitante, pois a mãe passa por momentos de indecisão sobre como agir, sentindo-se, então, dividida. É o que constatou, também, outro estudo com mães de bebês prematuros $^{8}$.

A ambivalência também foi um estado emocional vivenciado por mães acompanhantes de filhos hospitalizados, em que ficava dificil para essas mulheres assumirem a escolha de interromper as atividades domésticas para ficar com o filho internado. Todas se sentiam insubstituíveis para o filho; no entanto, as demais responsabilidades que tinham em casa demandavam sua atenção, o que gerava sentimento de impotência ${ }^{16}$.

É o que também expressam as mulheres deste estudo, quando tentam amparar a todos, tornando por vezes sua rotina desgastante; são solicitadas com frequência pelo filho que deixam em casa, por isso ficam, muitas vezes, sem saber como agir. Sabem que para se envolverem completamente no contexto 
de hospitalização do filho, precisariam estar desvinculadas de todos os contextos restantes além do hospital, no entanto, constatam que não é possível. Neste estudo, percebemos que é importante salientar que, a exemplo de outros estudos, um fator que pode aliviar o conflito de emoções e sentimentos da necessidade de dar conta de tudo e todos é a confiança que a mulher mostrou ter desenvolvido nos profissionais que cuidam e tratam de seu filho.

A segurança de deixar a criança em local seguro e com profissionais que demonstram solidariedade e afetividade, além da competência técnica, a libera para as demais atividades e deveres no ambiente doméstico, uma vez que para este muitas vezes ela não encontra quem a substitua integralmente ${ }^{8,17}$.

\section{DSC - Sentindo-se acolhida pela equipe de saúde}

[...] Onde eu mais tive apoio para aguentar até agora, mais de dois meses, e aquele medo ter passado, foi a convivência que eu tive aqui dentro do Hospital, a convivência também que ajuda. Criei um vínculo, também criei uma família sabe? Devido o apoio. [...] Com a ajuda de vocês conversando com a gente, então, é esse tipo de ajuda... a atenção, 0 carinho com meu filho, todo mundo ajudou, auxiliam ao que precisa. [...] a minha segunda familia passou a ser esses dias que eu passei fiquei aqui, cuidaram do meu filho, cuidaram de mim também...

Percebemos que é a partir da convivência das mulheres com os profissionais que elas referem ter superado seus medos. 0 convívio permite a formação de um vínculo, a tal ponto de sentirem-se até familiarizadas no ambiente de internação da criança.

Torna-se essencial que a comunicação e o relacionamento humano sejam valorizados e utilizados como instrumento na assistência, sendo esta uma das maneiras de despertar a sensibilidade, compreender o outro e integrar o trabalho de equipe $^{18}$.

Dessa forma, vale reiterar que as mães dos bebês prematuros deste estudo, ao demonstrarem que adquiriram confiança nas pessoas que a assistiram, sentiram-se mais tranquilas. Observam que a atenção individualizada dispensada a ela e ao filho faz com que se sintam, também, cuidadas, monstrando-se familiarizadas no contexto hospitalar. Neste estudo, é interessante observar que as mulheres demonstram que o tipo de ajuda que esperam da equipe, como o saber ouvir, falar e 0 cuidar, supera os avanços tecnológicos, não transparecendo em nenhum momento qualquer questionamento quanto à competência técnica dos profissionais. Este dado é corroborado por outro estudo ${ }^{12}$, no qual a competência técnica dos profissionais é dada como certa, e o que qualifica a assistência é a capacidade destes de interagir com a mãe e a criança. Podemos extrair deste discurso que a atenção e o carinho recebidos das pessoas são essenciais para inserção dessas mulheres no contexto de hospitalização do filho e em seu contexto doméstico, o que indiretamente pode proporcionar melhores condiç̃̃es subjetivas e objetivas para a manutenção da lactação e amamentação.

\section{CONSIDERAÇÕES FINAIS}

Percebemos que, embora a amamentação exclusiva ao peito seja um objetivo almejado, tanto pela mãe do prematuro como pela equipe, constatamos em nosso estudo que poucas mulheres amamentavam seus bebês ao peito, sem a necessidade de complemento lácteo, por ocasião da alta. A respeito desse fato, ponderamos que o período de amamentação sem o uso da sonda gástrica foi, para a maior parte dessas mulheres, o período crucial para se estabelecer ou não a eficiência da mamada ao seio, pois estas mães tiveram, em nosso entendimento, pouco tempo para lidar com o manejo da amamentação sob supervisão direta de profissionais, visto que as boas condições de saúde do filho 0 aproximavam da alta hospitalar.

Embora fossem consideradas aptas para lactar e amamentar, o que foi constatado no exame físico das mamas, verificamos que todas as mulheres do presente estudo exteriorizaram algum tipo de dificuldade para manter a produção láctea e amamentar seu bebê prematuro. As observações verbalizadas pelas mulheres do estudo mostram que a mãe do bebê prematuro vivencia continuamente um processo de avaliação, tanto de suas condições de manter a lactação e amamentação como das condições de saúde do filho, por meio das manifestações do comportamento dele, quando avaliam os riscos e benefícios para ambos durante esse processo.

No contexto deste trabalho, podemos inferir que o estímulo à ordenha para manutenção da lactação ficou prejudicado, tanto no contexto hospitalar como no doméstico. No primeiro, provavelmente, por haver um hiato na assistência à mulher, que se mostra descontinuada entre a unidade que assiste 0 bebê e a unidade de Alojamento Conjunto que assiste a mãe, carecendo de uma linguagem e ações combinadas para conciliar a necessidade de ambas, no que concerne aos meios de manutenção da lactação. No contexto doméstico, observamos que a preocupação materna em meio ao seu desejo e responsabilidade de desempenho de vários papéis, a manutenção da lactação e a amamentação perdem a força à medida que ela se reintegra em sua rotina. Não aparece mais a figura do profissional que a estimule e monitore nas ações de manutenção da lactação. Este processo torna-se cada vez mais, ao longo do período de internação, dependente das condições objetivas da criança de sugar e dar respostas biológicas e afetivas para a motivação materna.

0 conteúdo dos discursos também aponta para a importância da atuação da equipe no desenvolvimento de segurança e confiança no cuidado com a criança, no qual a qualificação da assistência reside na capacidade de acolhimento às necessidades maternas na mesma medida do que ela espera de seu contexto familiar e entorno social.

Acreditamos que os resultados encontrados no presente estudo possam fornecer subsídios para a reflexão de nossas práticas como profissionais, no que diz respeito às particularidades do aleitamento materno de cada mãe de bebê prematuro de nosso serviço. 


\section{Referências}

1. Merighi MB, Praça NS. Abordagens teórico-metodológicas qualitativas. Rio de Janeiro (RJ): Guanabara Koogan; 2003.

2. Silva IA. Amamentar: uma questão de assumir riscos ou garantir benefícios. São Paulo (SP): Robe; 1997.

3. Conselho Nacional de Saúde. Resolução nº 196, de 10 de outubro de 1996. Dispõe sobre diretrizes e normas regulamentadoras de pesquisas envolvendo seres humanos. Bioética 1996; 4(2 supl): 1525.

4. Lefèvre F, Lefèvre AMC. Depoimentos e discursos uma proposta de análise em pesquisa social. Brasília (DF): Líber Livro; 2005.

5. Méier PP. Breastfeeding in the special care nursery. Prematures and infants with medical problems. Pediatr Clin North Am 2001; 48(2): 425-42.

6. Serra SOA, Scochi CGS. Dificuldades maternas no processo de aleitamento materno de prematuros em uma UTI neonatal. Rev Latinoam Enfermagem 2004; 12(4): 597-605.

7. Nakano MAS. As mulheres e as diferentes posiç̃es de sujeito na prática do aleitamento materno. Acta Paul Enferm 2002; 15(4): $96-$ 101.

8. Caetano LC. Vivendo no método canguru: a tríade mãe-filho-família [tese de doutorado]. Ribeirão Preto (SP): Escola de Enfermagem de Ribeirão Preto/USP; 2004.

9. Gorgulho FR, Pacheco STA. Amamentação de prematuros em uma Unidade Neonatal: a vivência materna. Esc Anna Nery Rev Enferm 2008; 12(1): 19-24.
10. Javorski M, Caetano LC, Vasconcelos MGL, Leite AM, Socchi CGS. As representações sociais do aleitamento materno para mães de prematuros em unidade de cuidado canguru. Rev Latino-am Enfermagem 2004; 12(6): 890-98.

11. Silva IA. Construindo perspectivas sobre a assistência em amamentação: um processo interacional [tese livre-docência]. São Paulo (SP): Escola de Enfermagem/USP; 1999.

12. Belli MAJ. Mães com filho internado na UTI neonatal: um estudo sobre representações sociais [tese]. São Paulo (SP): Escola de Enfermagem/USP; 1999.

13. Brito MHA. Ser-mãe-de-prematuro: o cuidado inimitável da presença materna. [dissertação de mestrado]. Fortaleza (CE): Universidade Federal do Ceará; 2002. p. 106-07.

14. Bowlby J. Cuidados maternos e saúde mental. São Paulo (SP): Martins Fontes; 2002.

15. Oliveira I, Angelo M. Vivenciando com o filho uma passagem difícil e reveladora: a experiência da mãe acompanhante. Rev Esc Enferm USP 2000; 34(2): 202-08.

16. Siqueira LS, Sigaud CHS, Rezende MA. Fatores que apóiam e não apóiam a permanência de mães acompanhantes em unidade de pediatria hospitalar. Rev Esc Enferm USP 2002; 36(3): 270-75.

17. Bousso RS. Buscando preservar a integridade da unidade familia: a família vivendo a experiência de ter um filho na UTI pediátrica [tese de doutorado]. São Paulo (SP): Escola de Enfermagem/ USP; 1999.

18. Tronchin DMR. A experiência de tornarem-se pais de prematuro: um enfoque etnográfico. Rev Bras Enferm 2005; 58(1): 49-54. 